\title{
Trend of NFC Technology for Payment Transaction
}

\author{
Edi Purnomo Putra* ${ }^{\star 1}$ Fifilia $^{2}$, Hanny Juwitasary ${ }^{3}$ \\ Information Systems Department, School of Information Systems, Bina Nusantara University, \\ Jakarta, Indonesia 11480. \\ *Corresponding author, e-mail: eputra@binus.edu, fifilia1302@binus.ac.id, hjuwitasary@binus.edu
}

\begin{abstract}
Implementation of NFC Technology was developed to facilitate instant payment transaction such as purchase tickets, goods, or service to become one of the digital wallet besides to using credit cards. The high rate of mobile devices usage in Indonesia make many companies take advantage of this device as a media in electronic payment transactions, a lot of banking and financial product in Indonesia used this technology such as E-money, T-cash, Flazz, Ooredoo, Dompetku, XL-Tunaiku, Doku Wallet, Skye card, Artajasa MYNT and many more. The technique that used in this research to prove the hypotheses was Structural Equation Model (SEM) using Smart PLS software, we will used questionnaire and literature review method to found trend of NFC use. The population from which to draw conclusion was defined as all individual capable use NFC Technology for payment transaction. In this study, we will investigate NFC use in Indonesia, The proposed research model was develop by TAM Framework with some dimension from NFC study literature that is Mobile Payment Knowledge, Technology, Trust, Behaviour and Compatibility into the model, in order to determine the significant factor that influence of NFC use in Indonesia.
\end{abstract}

Keywords: NFC, digital wallet, instant payment, TAM model, SEM, PLS

Copyright $@ 2018$ Universitas Ahmad Dahlan. All rights reserved.

\section{Introduction}

Mobile device make up the faster growing segment of computer device. The two most commonly used application environment are Apple's iOS and Android [1]. NFC allowing the integration of service from various application into one single mobile [2], the mobile payment are payment for goods, service, and bill with mobile device by wireless and communication technology [3], its economic attractiveness because it is based on open standards and users are not obliged to pay licencing fees [4]. NFC-based mobile payment systems also use the secure element on a mobile device to protect sensitive data and for cryptographic processing[5]. Worldwide, by end 20142 million smartphone owner had used their device at least once a month to make contactless NFC in-store payments at retail outlets[6]. NFC not only brings simplicity to our lives, but also creates additional opportunities for entrepreneurs as well [7], Although mobile payments offer promising business perspectives, technical hurdles need to be solved [8].

NFC technology has begun to be used in Indonesia, a lot of banking and financial product that using this technology such as E-money, T-cash, Flazz, Ooredoo, Dompetku, XLTunaiku, Doku Wallet, Skye card, Artajasa MYNT and many more [9]. For example T-cash, already has 800.000 users from the target of 10 million users in 2017 [10]. Based on data wearsocial.org (2014) Indonesia has a high level of use mobile device at $112 \%$ or about 280 million unit. The high rate of mobile devices usage in Indonesia make many companies take advantage of this device as a media in electronic payment transactions [11]. Considering mobile payment as adisruptive technology, innovation factors play an important role in the behavioral intention leading to its adoption [12].

The aim of this work is to investigate the acceptance of NFC technology for payment thought mobile in indonesia, its important to determine the factor that influence customer conduct payment transaction by NFC. Thus, in this paper we proposed a model of factor influencing NFC use in Indonesia. 


\section{Related Works}

NFC allows to digitally transferring money from the payer's bank to the payee's bank. This approach eliminates the need for physical cash and also serves all types of payment and identity needs [13]. This technology enable instantaneous transmission of data by simply approaching a device in distance less than $4 \mathrm{~cm}$ to receiver [14]. NFC technology more suitable for payment than traditional, NFC payment primarily lead to faster and easier payment at the point of sale [15]. Taking into account that growth in the use of NFC technology throughout the world is a reality [14], so it is necessary to discuss the success of NFC for payment, especially in Indonesia.

This study we propose TAM framework that use as a fundamental study about information system technology [16]. There are 2 dimension of TAM that is Perceived Ease of use and Perceived of usefulness [17] then mapping with some dimension from previous research about NFC[18] such as Mobile Payment Knowledge, Technology, Trust, Behaviour and Compatibility as shown in Table 1.

Table 1. Mapping Dimension

\begin{tabular}{|c|c|c|c|c|c|c|}
\hline Dimension \Title & $\stackrel{\underline{n}}{\underline{2}}$ & $\begin{array}{l}0 \\
\frac{D}{0} \\
\frac{0}{3} \\
\frac{1}{2} \\
\frac{0}{x}\end{array}$ & 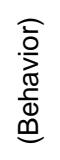 & 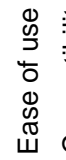 & 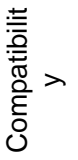 & 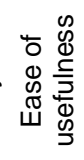 \\
\hline $\begin{array}{l}\text { Understanding The Factors Driving NFC-Enabled Mobile Payment Adoption: An } \\
\text { Empirical Investigation. (Hongxiu Li, 2014) }\end{array}$ & - & $\mathrm{x}$ & - & - & - & $\mathrm{x}$ \\
\hline $\begin{array}{l}\text { NFC Technology Acceptance for Mobile Payments: A Brazilian Perspective. } \\
\text { (Francisco Montoro-Ríos, 2016) }\end{array}$ & - & - & - & - & - & $x$ \\
\hline $\begin{array}{l}\text { Mobile payment: Understanding the determinants of customer adoption and intention } \\
\text { to recommend the technology. (Tiago Oliveira, 2016). }\end{array}$ & - & & $\mathrm{x}$ & - & - & \\
\hline Investigation of Users Perception Of Using NFC Mobile Payment (Gege Gao, 2015). & $\mathrm{x}$ & - & - & $x$ & $x$ & $\mathrm{x}$ \\
\hline $\begin{array}{l}\text { Near Field Communication - Its Adoption Process and Technology Acceptance. } \\
\text { (Philipp Immanuel Bernhard, 2014). }\end{array}$ & $x$ & - & - & - & - & - \\
\hline $\begin{array}{l}\text { Typical Presentation to Evaluate NFC Technology in Electronic Mobile Payments. } \\
\text { (Shima Asadbeigi, 2016) }\end{array}$ & $\mathrm{x}$ & $\mathrm{x}$ & - & - & - & - \\
\hline
\end{tabular}

The research model is shown in Figure 1, this study follow from previous studies combine TAM model with variable shown in Table 1 for proposed new model. The combination of theoretical approach was made with assuming that an integrative perspective provides a more complete account of the causal mechanisms underlying the relationships as well as unique insights that cannot be obtained with a single theory driven model [19].

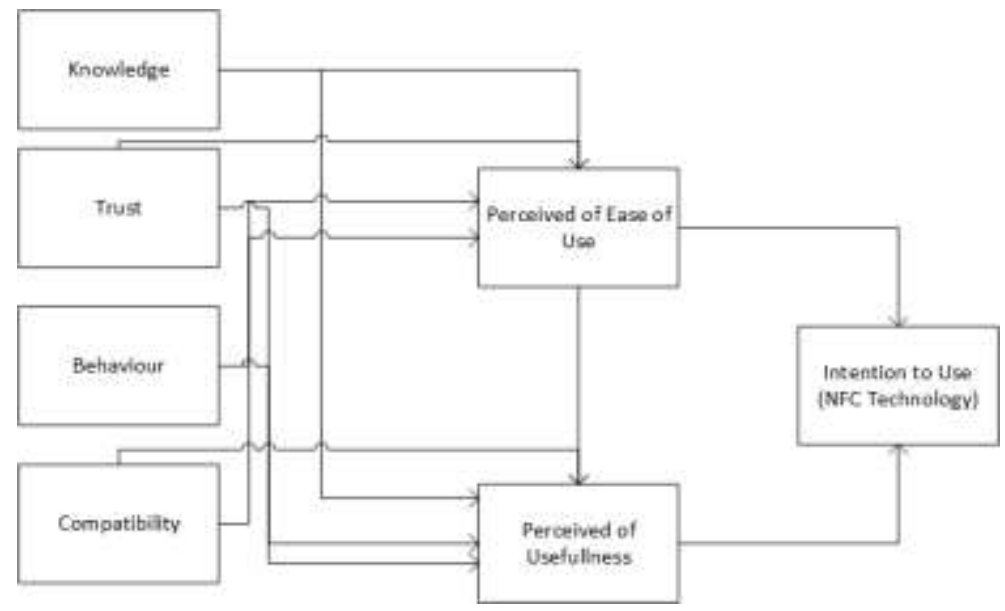

Figure 1. Conceptual framework 


\section{Result and Analysis}

The technique that used in this research to prove the hypotheses was Structural Equation Model (SEM) using Smart PLS software.

\subsection{Sample}

This research used questionnaire and literature review method that used to see trend of NFC use. The population from which to draw conclusion was defined as all individual capable use NFC Technology for payment transaction in Indonesia. Data collecting begin from 21 august 2017 until 15 September 2017, using the online survey platform. Total we had 85 valid sample sizes from 108 questionnaire that filled out by respondents who have use NFC Technology for payment transaction in Indonesia.

\subsection{Hypotheses}

From the research model, we formulated the following hypotheses and tested using SEM technique. The model is describe in figure 2 below:

H1 :Trust effectiveness will have positive effect on Ease of use.

H2 : Trust effectiveness will have positive effect on Ease of usefulness.

H3 : Knowledge effectiveness will have positive effect on Ease of use.

$\mathrm{H} 4$ : Knowledge effectiveness will have positive effect on Ease of usefulness.

H5 : Behavior effectiveness will have positive effect on Ease of use.

H6 : Behavior effectiveness will have positive effect on Ease of usefulness.

$\mathrm{H} 7$ : Compatibility effectiveness will have positive effect on Ease of use.

H8 : Compatibility effectiveness will have positive effect on Ease of usefulness.

H9 : Ease of use effectiveness will have positive effect on Ease of usefulness NFC.

H10 : Ease of use effectiveness will have positive effect on NFC use

$\mathrm{H} 11$ : Ease of usefulness effectiveness will have positive effect on NFC use

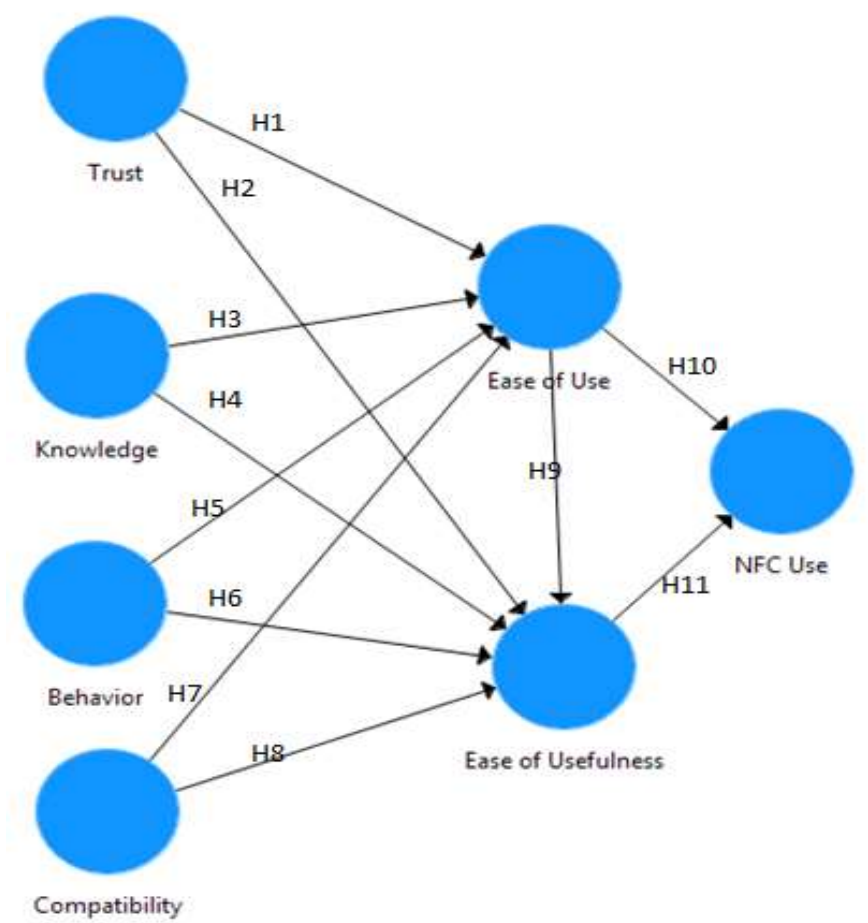

Figure 2. Hypotheses mapping

\subsection{Demography of the Sample}

The demography of the sample is tabulate in Table 2. Based on questioner filled out by the respondent sample consisted of $72 \%$ male and $28 \%$ female. Majority of the respondents 
about $41 \%$ were $20-24$ years old, about $36 \%$ were below 20 years and about $22 \%$ were above 24 years old. About 93\% respondents are domiciled in Jabodetabek (Jakarta-Bogor-DepokTangerang- Bekasi) and about $17 \%$ domiciled in outside Jabodetabek. Based on variable frequency using NFC majority respondent, about $80 \%$ were using NFC $0-1$ times a week, and about $20 \%$ were using NFC more than 1 times a week.

Table 2. Data Demography of Sample

\begin{tabular}{lcc}
\hline Variable & N & Percentage \\
\hline Gender & & \\
$\quad$ Male & 61 & $72 \%$ \\
$\quad$ Female & 24 & $28 \%$ \\
Age & & \\
$15-19$ & 31 & $36 \%$ \\
$20-24$ & 35 & $41 \%$ \\
$25-29$ & 18 & $21 \%$ \\
$>=30$ & 1 & $1 \%$ \\
Domicile & 17 & $20 \%$ \\
Tangerang & 56 & $66 \%$ \\
Jakarta & 2 & $2 \%$ \\
Bali & 4 & $5 \%$ \\
Sumatra & 4 & $5 \%$ \\
Bekasi & 2 & $2 \%$ \\
Bogor & & \\
Frequency Using NFC & 68 & $80 \%$ \\
0-1 Times a Week & 68 \\
2-3 Times a Week & 12 & $14 \%$ \\
4-5 Times a Week & 4 & $5 \%$ \\
More than 5 a Week & 1 & $1 \%$ \\
\hline
\end{tabular}

\subsection{Validity Test}

\subsubsection{Convergent Validity}

With regard to Factor Loadings [17], recommend that Standardized Regression Weights obtained should be 0.5 or higher, ideally 0.7 or higher and at a minimum statistically significant. Figure 3 represent all item factor loading exceeds 0.5 , thus, there is no need delete item from the model.

In other way convergent validity is judged to be adequate when composite reliability exceeds 0.70 and average variance extracted exceeds 0.50 [17]. Figure 5 represent CR exceeds 0.7 and Figure 6 represent AVE exceeds 0.5 . Thus, convergent validity for all the constructs was established.

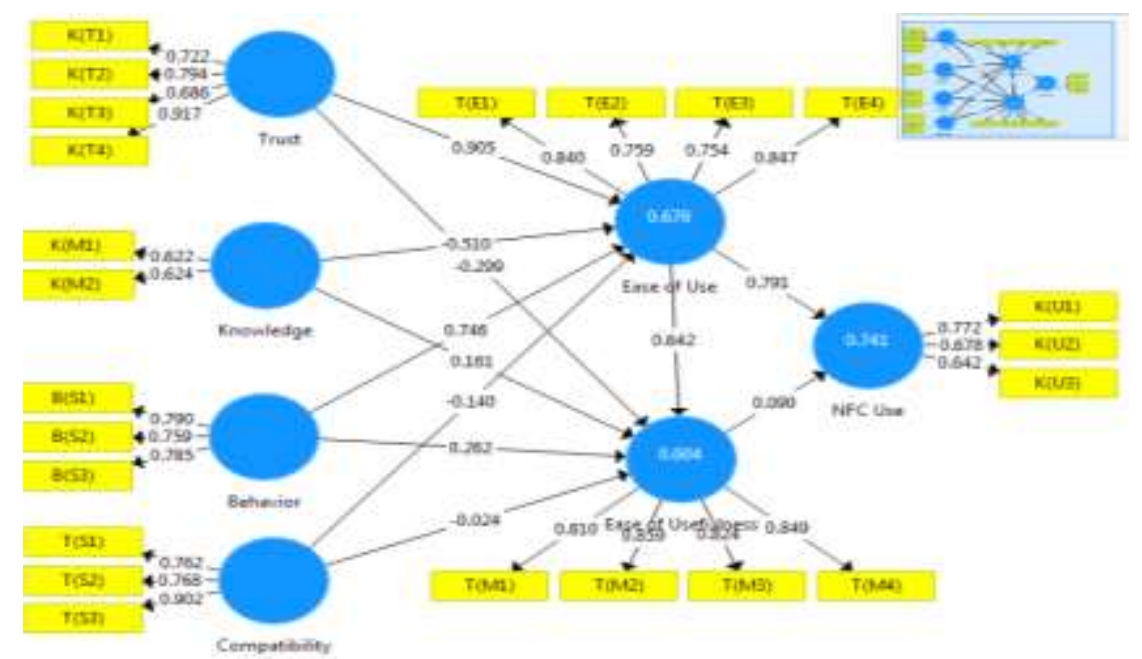

Figure 3. Result of research model 


\subsubsection{Discriminant Validity}

In our study discriminant validity is established when variance shared between a construct and any other construct in the model is less than the variance that a construct shares with its own indicators[20]. To get satisfactory discriminant validity, the square root of AVE for each construct should be greater than the squared correlation between the constructs [20].

$$
\mathrm{AVE}=\frac{\sum \lambda_{1}^{2}}{\sum \lambda_{1}^{2}+\sum \operatorname{arr}\left(\theta_{1}\right)}
$$

The data in Figure 4 represent the square root of average variance extracted (AVE) $(0.859,0.881,0.854,0.880,0.833,0.810$ and 0.845$)$ greater than the squared correlation between the constructs. Thus, discriminant validity for all the constructs was established.

\begin{tabular}{|l|r|r|r|r|r|r|}
\hline & Behavior & Compatibility & Ease of Use & Ease of Useful... & Knowledge & NFC Use \\
\hline Behavior & 0.859 & & & & & \\
\hline Compatibility & 0.741 & 0.881 & & & \\
\hline Ease of Use & 0.662 & 0.628 & 0.854 & & \\
\hline Ease of Usefuln... & 0.588 & 0.525 & 0.674 & 0.880 & \\
\hline Knowledge & 0.608 & 0.617 & 0.691 & 0.493 & 0.833 & \\
\hline NFC Use & 0.757 & 0.620 & 0.696 & 0.565 & 0.763 & 0.810 \\
\hline Trust & 0.575 & 0.631 & 0.679 & 0.468 & 0.734 & 0.617 \\
\hline
\end{tabular}

Figure 4. Discriminant validity

\subsubsection{Composite Realibility}

The value received for composite realibility is exceeds 0.7 [17]. Figure 5 represent all construct composite realibility exceeds 0.7 , thus composite realibility for all construct was established.

$$
N-\frac{\sum \mu 1^{2}}{\sum(2)^{2}+\sum v(\varepsilon)}
$$

\begin{tabular}{|l|r|} 
& Composite Rel... \\
\hline Behavior & 0.894 \\
\hline Compatibility & 0.912 \\
\hline Ease of Use & 0.915 \\
\hline Ease of Usefuln... & 0.932 \\
\hline Knowledge & 0.819 \\
\hline NFC Use & 0.851 \\
\hline Trust & 0.909 \\
\hline
\end{tabular}

Figure 5. Composite reliability

\subsubsection{Average Variance Extracted (AVE)}

The value received for Average Variance Extracted AVE > 0.5 [17]. Based on Figure 6 Average Variance Extracted all constructs greater than 0.5. thus, all the constructs were adequate. 


\begin{tabular}{|l|r|}
\hline & AVE \\
\hline Behavior & 0.737 \\
\hline Compatibility & 0.776 \\
\hline Ease of Use & 0.730 \\
\hline Ease of Usefuln... & 0.775 \\
\hline Knowledge & 0.694 \\
\hline NFC Use & 0.657 \\
\hline Trust & 0.714 \\
\hline
\end{tabular}

Figure 6. Average variance extracted

\subsubsection{Cronbach Alpha}

In order to ensure that the variable for each factor were internally consistent we tested internal consistency with Cronbach's alpha test that revealed all value $>0.7$ [17]. Figure 7 depict knowledge have value 0.559 below standard of Cronbach's alpha test. Thus, knowledge construct must be deleted from the model.

\begin{tabular}{|c|c|c|c|}
\hline \multicolumn{2}{|c|}{ 掉育 Cronbachs Alpha } & Matrix & \\
\hline & & ronbachs $\mathrm{Al}$ & Ip... \\
\hline Behavior & & & 822 \\
\hline Compatibility & & & 856 \\
\hline Ease of Use & & & 876 \\
\hline Ease of Usefuln... & & & 903 \\
\hline Knowledge & & & 559 \\
\hline NFC Use & & & 738 \\
\hline Trust & & & 867 \\
\hline
\end{tabular}

Figure 7 Cronbach's Alpha

\subsubsection{Good of Fit-inner Model Test}

Good of Fit Model is measured uses the R-square latent variable which interpretation is equal with regression. The $\mathrm{Q}$-square $>0$ indicates the model has the predictive relevance, otherwise, if the $Q$-square $\leq 0$ indicates the model does not has enough the predictive relevance [21]. The formula of the $\mathrm{Q}$-square calculation is:

$$
Q^{2}=1-\left(1-R 1^{2}\right)\left(1-R 2^{2}\right) \ldots\left(1-R p^{2}\right)
$$

The value of $Q^{2}$ has the range value in $0<Q^{2}<1$ which if the value is close to 1 that indicates the model is better. The result of the calculation as follows:

$$
\begin{aligned}
Q^{2} & =1-(1-0.607)(1-0.492)(1-0.501) \\
& =0.09004
\end{aligned}
$$

From the calculation above, the result shown 0.09004 is close to 1 that indicates good predictive relevance.

\subsubsection{Test of Hypotheses}

The test of hypothesis can be seen from T-Statistic and Probability value ( $p$-value). In hypothesis testing uses t-statistic then the alpha is $5 \%$ of the value is 1.98 . Thus, the criteria of 
hypothesis result are Hypothesis Alternative $(\mathrm{Ha})$ are accepted and Null Hypothesis $(\mathrm{H} 0)$ are rejected, if the t-statistic value is $>1.986$. If $p$-value $<0.05$ then $\mathrm{Ha}$ is accepted [17].

Based on test of hypotheses the value allow us to determine that behavior effectiveness will have positive effect on Ease of use NFC, obtained empirical support (TStatistic=2.92;p<0.05) supporting hypothesis 5. The perception Ease of use in turn effectiveness will have positive effect on Ease of usefulness, as proposed in H9 (T-Statistic $=4.077 ; p<0.05)$ this is confirm the result of previous study acceptance of NFC Technology [14].

The relationship proposed by $\mathrm{H} 10$ between Ease of use and NFC use it was supported(T-Statistic $=5.53 ; p<0.05)$. Meanwhile, the statement proposed in hypothesis 1 that Trust effectiveness will have positive effect on Ease of use NFC it was supported (TStatistic=3.43; $p<0.05)$.

Table 3. Path Coefficients

\begin{tabular}{lll}
\hline & T Statistics & P Values \\
\hline Behavior $->$ Ease of Use & 2.926 & 0.004 \\
Behavior -> Ease of Usefulness & 1.218 & 0.224 \\
Compatibility -> Ease of Use & 1.098 & 0.273 \\
Compatibility -> Ease of Usefulness & 0.448 & 0.654 \\
Ease of Use -> Ease of Usefulness & 4.077 & 0.000 \\
Ease of Use -> NFC Use & 5.536 & 0.000 \\
Ease of Usefulness -> NFC Use & 1.525 & 0.128 \\
Trust $->$ Ease of Use & 3.437 & 0.001 \\
Trust $->$ Ease of Usefulness & 0.357 & 0.722 \\
\hline
\end{tabular}

\section{Discussion and Conclusions}

This research uses quantitative method as a method in data processing by using literature review methods and benchmarking related to TAM and its relation to the NFC use. In this research we selected several dimensions that have been used in previous research such as Trust, Knowledge (Behavior), Easy to use, Conformity and Convenience dimension to create research model that combined with TAM model for NFC use. During the research we also have limitation such as in collection data from loyalty user who use NFC.

This study analyze the trend of NFC mobile payment system use in Indonesia, there is many determining factor influence successful implementation of mobile payment especially using NFC Technology. In the data processing we have removed 1 dimension that does not meet the requirements of Structural Equation Modeling (SEM) that is the knowledge dimension, then we reprocessing data to make sure that the data is established for next step. As discuss in the test of hypotheses we can conclude there are four hypotesis $\mathrm{H} 5, \mathrm{H} 9, \mathrm{H} 10$, and $\mathrm{H} 1$ are significant positive influence and the rest is rejected.

\section{References}

[1] M Ketel, T Shumate. Bring Your Own Device : Security Technologies. 2015.

[2] M Al-tamimi, A Al-haj. for NFC Mobile Payment Applications. 2017: 827-832.

[3] G Arcese, G Campagna, S Flammini, O Martucci. Near Field Communication: Technology and Market Trends. Technologies. 2014; 2(3): 143-163.

[4] F Liébana-cabanillas, IR De Luna, F. Montoro-. Intention to use new mobile payment systems: a comparative analysis of SMS and NFC payments. Econ. Res. Istraživanja, 2017; 30(1): 724-742.

[5] Y Wang. Mobile Payment Security, Threats, and Challenges. 2016.

[6] TJ Gerpott, P Meinert. Manuscript ID: ECRA-D-16-00341R4/ELERAP 704 Chair of Strategic and Telecommunications Management Chair of Strategic and Telecommunications Management Mercator School of Management. Electron. Commer. Res. Appl., 2017.

[7] V Coskun, B Ozdenizci, K Ok. The Survey on Near Field Communication. 2015: 13348-13405.

[8] M De Reuver, J Ondrus. When technological superiority is not enough: The struggle to impose the SIM card as the NFC Secure Element for mobile payment platforms. Telecomm. Policy, 2016: 1-10.

[9] Enricko Lukman. Kumpulan e-money Indonesia yang bisa Anda gunakan untuk belanja. 2017. [Online]. Available: https://id.techinasia.com/kumpulan-pemain-emoney-indonesia-yang-bisa-anda-gunakanuntuk-belanja. [Accessed: 31-May-2017].

[10] Ervina Anggraini. 2017, Telkomsel Targetkan 10 Juta User T-cash, 2017. [Online]. Available: http://www.cnnindonesia.com/teknologi/20161005161907-213-163514/2017-telkomsel-targetkan-10juta-user-t-cash/. [Accessed: 30-May-2017]. 
[11] I Conference, C Science, C Intelligence. A Model of Factors Influencing Con sumer's Intention To Use E-Payment System in Indonesia. Procedia-Procedia Comput. Sci., 2015; 59(Iccsci): 214-220.

[12] T Oliveira, M Thomas, G Baptista, F Campos. Computers in Human Behavior Mobile payment: Understanding the determinants of customer adoption and intention to recommend the technology. Comput. Human Behav., 2017; 61, no. 2016: 404-414.

[13] A Majumder, A Kumar. Meets All User Payment. no. january, 2017.

[14] F Montoro-ríos, F Liébana-cabanillas. NFC technology acceptance for mobile payments: A Brazilian Perspective. 2016; 19(63): 82-103.

[15] S Burkard. Near Field Communication in Smartphones. Abc. 2012: 1000.

[16] G Gao. Investigation of Users Perception of Using Nfc Mobile Payment. 2015: 1-74.

[17] M Moslehpour. e-Purchase Intention of Taiwanese Consumers: Sustainable Mediation of Perceived Usefulness and Perceived Ease of Use. 2018.

[18] S Asadbeigi, A Abdollahi, S Shokohyar. Typical presentation to evaluate NFC. 2016; 3: 109-118.

[19] JD Jackson, MY Yi, JS Park. Information \& Management An empirical test of three mediation models for the relationship between personal innovativeness and user acceptance of technology. Inf. Manag. 2013; 50(4): 154-161.

[20] F Ali. Article information :An Assessment Of The Use Of Partial Least Squares Structural Equation Modeling (Pls-Sem) In Hospitality Research. 2016.

[21] JFH Jr, L Hopkins, M Georgia, S College. Partial least squares structural equation modeling (PLSSEM) An emerging tool in business research. 2014. 